\title{
A Implicação do Afeto na Psicologia do Desenvolvimento: uma Perspectiva Contemporânea
}

Affect in Developmental Psychology: a Contemporary Perspective

El Relevancia del Afecto en la Psicología del Desarrollo: una Perspectiva Contemporánea

José Carlos Chaves Brazão

Universidade Federal Fluminense

http://dx.doi.org/10.1590/1982-370302222013 
Resumo: Este texto aborda o papel do afeto no desenvolvimento humano, sua implicação na emergência das funções cognitivas superiores, incluindo a linguagem, sua importância como mediador nas relações intersubjetivas e, principalmente, na socialização da criança. Tomamos como referência autores clássicos, como Henri Wallon, e contemporâneos, como Maturana, conjugados sob uma perspectiva desenvolvimentista. Apresentamos, sucintamente, os trabalhos de Daniel N. Stern, cuja teoria da emergência dos sensos de si, compreendidos como perspectivas autônomas para organização da experiência subjetiva, tornou-se referência entre teóricos e clínicos da Psicologia do Desenvolvimento, pela descrição de conceitos tais como a sintonia afetiva, os afetos de vitalidade, a percepção amodal, dentre outros, tão importantes para a compreensão dos processos relacionais humanos. Salientamos, também, as intervenções de base afetiva, visando estimular os processos básicos de interafetividade, compreendidos por serem deficitários em transtornos do desenvolvimento tais como o autismo, enfatizando a sua relevância. Concluímos que a interafetividade é um fator essencial para o desenvolvimento saudável da criança, um agente de socialização, e um poderoso recurso interventivo na clínica.

Palavras-chave: Afeto. Intersubjetividade. Desenvolvimento. Autismo.

Abstract:This paper examines the role of affect, which is the experience of a feeling or emotion, in human development; its implication in the emergence of higher cognitive functions, including language; its importance as a mediator in interpersonal relationships and, specially, in the socialization of children. Henri Wallon and other contemporaries of his, such as Maturana, have examined this topic from a developmental perspective. This paper advances Daniel N. Stern's theory of the senses of self, understood as autonomous perspectives for organizing subjective experiences as referenced in theoretical and clinical developmental psychology for its description of concepts such as affect attunement, vitality affect, and amodal perception, among others, all very important for the comprehension of human relational processes. Further discussed are interventions based on affect stimulation through basic interaffective processes, known to be deficient in developmental disorders such as autism, emphasizing its relevance. We conclude that interaffectivity is an essential factor for healthy child development, an agent of socialization, and a powerful interventional resource in clinical work.

Keywords: Affect; intersubjetivity; development; autism.

Resumen: En este trabajo se aborda el papel del afecto en el desarrollo humano, su relevancia en la aparición de las funciones cognitivas superiores, incluso el idioma, y su importancia como mediador en las relaciones interpersonales y principalmente la socialización del niño. Apoyamos este trabajo en autores clásicos, como Henri Wallon, y contemporáneos como Maturana, combinados bajo una perspectiva de desarrollo. Presentamos, en pocas palabras, el trabajo de Daniel N. Stern cuya teoría de la aparición de los sentidos de sí mismo, entendidos como perspectivas autónomas de organización de la experiencia subjetiva, se convirtió en una referencia entre teóricos y clínicos de la Psicología del Desarrollo, mediante la descripción de conceptos como la sintonía afectiva, los afectos de vitalidad, la percepción amodal, entre otros, tan importantes para la comprensión de los procesos relacionales humanos. También hacemos hincapié en las intervenciones de base afectiva para estimular los procesos de interafetividad básica, entendiendo que son deficientes en los trastornos del desarrollo, como el autismo, haciendo hincapié en su importancia. Llegamos a la conclusión de que la interafetividad es un factor esencial para el desarrollo saludable del niño, un agente de socialización, y un recurso de gran alcance en la intervención clínica.

Palabras clave: Afecto. Intersubjetividade. Desarollo. Autismo. 
1 Piaget (1970) entendia que as funções cognitivas superiores eram um prolongamento da inteligência sensório-motora, característica elementar do organismo biológico.

\section{A implicação do afeto na Psicologia do Desenvolvimento: uma perspectiva contemporânea}

O objetivo deste trabalho é delinear a implicação do afeto nos processos do desenvolvimento humano e apontar a crescente relevância que lhe tem sido atribuída em estudos contemporâneos na Psicologia do Desenvolvimento. Tomamos, como base, pesquisas organizadas de acordo com a perspectiva desenvolvimentista em Psicologia que envolvem o desenvolvimento atípico, a linguagem e a comunicação pré-verbal, bem como os trabalhos de autores já conhecidos nessa área, onde tem sido destacado o caráter imprescindível das capacidades inatas que o ser humano possui, manifestas desde a mais tenra idade, para compartilhar estados afetivos, sem as quais seu desenvolvimento ficaria comprometido. Neste intuito, trabalharemos com concepções tais como: conexão afetiva (Fiore-Correia \& Lampreia, 2012; Hobson, 2002), sintonia afetiva (Brazão, 2008, 2012) - affect attunement (Stern, 1985, 1995, 2004, 2010) -, intersubjetividade primária e secundária (Trevarthen \& Aitkhen 2001), principalmente, as quais podem ser definidas como variantes conceituais para fenômenos afetivos observados no desenvolvimento humano típico.

O afeto no contexto teórico da Psicologia do Desenvolvimento nem sempre ocupou um lugar de destaque. De fato, pode-se apontar que, até a metade do século XX, as teorias hegemônicas nesse campo lhe dispensavam um papel secundário ou mesmo pouco significativo e, embora não negassem a função do afeto nos processos do desenvolvimento, não reconheciam o lugar de mediador que ele ocupa nas relações intersubjetivas, como é sugerido por Maturana (1998, 2001), Maturana e Varela (1984), Maturana e VerdenZöller (1993), Vasconcellos e Valsiner (1995), e Wallon (1968, 1971, 1986).

Instigada pela exigência de se alinhar com uma epistemologia estabelecida sobre ideais científicos, a Psicologia, como domínio de saber ainda claudicante em seus primeiros passos, incorpora, em suas principais linhas de pesquisa, os fundamentos da metodologia positivista e, com isso, muitas de suas teorias são construídas sobre as supostas objetividade e finalidade defendidas pelas ciências naturais (Passos, 1992). Dessa forma, a atenção dos psicólogos permaneceu voltada para a elaboração de medidas, para a quantificação de capacidades, para a comparação do desempenho e para o desenvolvimento das faculdades cognitivas (Piaget, 1964, 1967, 1970), estruturadas pela maturação sequencial de competências geneticamente determinadas (Brazão, 2008). Como suporte para estes ideais, modelos da Biologia genética, representante das ciências naturais, são tomados como diretores para os processos do desenvolvimento humano, que passa a ser pensado como o desdobramento de padrões hereditários que guardam quase que total independência em relação ao meio ambiente e ao contexto sócio-histórico. Temos a Epistemologia Genética de Piaget (1970) como uma das teorias mais eminentes deste período. Nela, as funções de assimilação e acomodação, correspondentes cognitivas das funções orgânicas básicas ${ }^{1}$, em sua mecânica circular, criavam a condição para que o processo de desenvolvimento se desdobrasse mantendo com o ambiente uma relação de adaptação, desencadeada pelas próprias necessidades do organismo. Pois, para o autor, toda a exploração do meio ambiente se dava em função de uma necessidade fundamentalmente biológica (Piaget, 1970). Cabe acrescentar que o apoio filosófico para esta ideologia tinha sua maior influência derivada do pensamento cartesiano, como se acompanha em:

\footnotetext{
Desde há três séculos que todos somos, direta ou indiretamente, alimentados pelo pensamento cartesiano, dado que, desde há três séculos justamente, todo o pensamento europeu, todo o pensamento filosófico, pelo menos, se orienta e se determina em relação a Descartes (Koyré, 1963 p. 3).
}

Não há na filosofia de Descartes uma negação do afeto, ou das emoções, como características humanas, mas ocorre a valorização 
da razão - faculdade da alma - através da afirmação identitária entre a existência e o eu pensante, sintetizada na célebre fórmula do cogito: "Penso, logo existo" (Descartes, 1641/1999; Koyré, 1963), com o consequente detrimento das animações mecânicas do corpo - sede das paixões, dos vícios e das fraquezas (Descartes, 1641/1999; Koyré, 1963). Pois, para o filósofo, o corpo mecânico era pertinente a qualquer espécie do reino animal, sendo a razão o que justamente propiciava a distinção do homem nesse reino, destacando-o no plano da criação. Dessa forma, tendo como eixo diretor o imperativo positivista, que dominava a metodologia científica do final do século XIX até meados do século XX (Passos, 1992) e, como vetor de orientação, a filosofia racionalista cartesiana a permear todo o pensamento ocidental da época ficava construída uma ideologia que estimulava a pesquisa de determinados aspectos do desenvolvimento humano (mormente aqueles ligados às faculdades racionais), desqualificando, ou mesmo negando, a investigação de outros, cuja natureza ou função pouco significava diante dos avanços tecnológicos e das conquistas sociais atribuídas aos primeiros.

\section{O avanço do afeto na Psicologia do Desenvolvimento}

Sob a influência da filosofia marxista e das transformações profundas que toda a Europa sofria (porque não dizer, todo o Ocidente), ao final dos anos 1960 e início dos anos 1970, as ciências humanas, em geral, e especialmente a Psicologia, incorporam as concepções da corrente sócio-histórica aos seus ideais teóricos. Dessa forma, efetua-se um deslocamento na orientação ideológica para se pensar as produções sociais e seus processos constitutivos. O desenvolvimento humano passa, então, a ser concebido não mais a partir de determinações genéticas, como o desdobramento de padrões hereditários, mas na convergência e na interface das capacidades biológicas com os processos culturais, em um dado momento histórico e social, numa perspectiva dialógica e co-construtivista. As relações sociais são ininterruptamente coconstruídas e o desenvolvimento humano é idealizado como um processo contínuo, desde o nascimento até a morte, dentro de ambientes culturalmente organizados e regulados nas interações sociais (Valsiner, 1988; Vasconcellos \& Valsiner, 1995).

Autores como Henri Wallon (um dos primeiros a introduzir na Psicologia os conceitos do materialismo dialético) consideram a criança como estando inserida no social desde seu nascimento e destaca a anterioridade dos processos afetivos a qualquer outro tipo de comportamento (Wallon, 1968, 1971, 1986). Wallon, com forte base fisiológica em seus estudos, enfatiza o caráter das emoções como veículo de expressão afetiva e como agente mediador intersubjetivo. Ele proclama que todo o contato social entre a criança e seu meio (o qual tem fundamentalmente duas funções: a de ambiente, contexto ou campo de aplicação de condutas; e a de condição, recurso, instrumento de desenvolvimento) (Wallon, 1986) é produzido e mediado por afetos/emoções. Na concepção do autor, antes da atualização da competência linguística, a criança se comunica com seu ambiente basicamente pela linguagem do corpo, através do que ele chama de diálogo tônico ou motricidade emocional (Vasconcellos \& Valsiner, 1995; Wallon, 1942, 1968, 1971), precursor da linguagem e condição para o desenvolvimento das funções cognitivas superiores. Para Wallon, a imitação - atividade intimamente ligada ao desenvolvimento da fala, da capacidade para compartilhar estados subjetivos e às demais competências sociais humanas - encontra sua possibilidade a partir do contato afetivo intersubjetivo, devido a certa sintonia empática, união mimética (Vasconcellos \& Valsiner, 1995), estabelecida entre o sujeito que imita e aquele que é imitado (Vasconcellos \&Valsiner, 1995; Wallon, 1942, 1968, 1971). Dessa maneira, fica destacado o papel que o afeto ocupa em sua teoria, como elemento central para a socialização do indivíduo e para o desenvolvimento de suas capacidades de interação com o ambiente.

Os afetos/emoções, embora possam receber conceituações distintas de acordo com o 
referencial teórico no qual sejam definidos, podem ser concebidos como "disposições corporais dinâmicas que especificam os domínios de ações" nos quais o ser vivo, em especial o ser humano, vai desenvolver suas relações (Maturana, 2001, p.129). Segundo Maturana, todo sistema racional fundamenta-se sobre disposições afetivo-emocionais que orientam as coordenações de ações (Maturana, 1998, 2001; Maturana \& Varela, 1984; Maturana \& Verden-Zöller, 1993). Sendo assim, as premissas que balizam as ações sociais de um ser humano, incluindo suas tendências políticas, profissionais e intelectuais, são definidas, primeiramente, pelos seus estados afetivo-emocionais, ou, utilizando os termos da filosofia de Spinoza, pelas relações de composição afetiva que estabelecem. No escólio da proposição nove da parte III da Ética, um dos principais trabalhos que o filósofo produziu, lê-se:

Torna-se assim, evidente, por tudo isso, que não é por julgarmos uma coisa boa que nos esforçamos por ela, que a queremos, que a apetecemos, que a desejamos, mas, ao contrário, é por nos esforçarmos por ela, por querê-la, por apetecê-la, por desejá-la, que a julgamos boa (Spinoza, 2007 p. 177).

Ainda, segundo Spinoza cada indivíduo pode ser definido como um grau de potência, ou seja, por possuir certo poder de afetar e de ser afetado por outros indivíduos. $\mathrm{Na}$ concepção do filósofo fica entendido que o indivíduo interage em seu ambiente social por meio dos seus afetos, estabelecendo relações dinâmicas, mutáveis, de acordo com os encontros que realiza e em consonância com sua potência afetiva. Para Spinoza, cada encontro guarda a potência de fazer emergir algo ainda desconhecido de cada indivíduo, devido à sua constituição múltipla e pelas relações de composição ou decomposição que se estabelecem nesses encontros. Essa característica faz com que sua filosofia se alinhe com a perspectiva desenvolvimentista em Psicologia do Desenvolvimento, uma vez que Spinoza privilegia os encontros como fatores de deflagração da potência individual, ficando em relevo o caráter relacional de seu sistema de pensamento.
Seguindo o caminho de Wallon, cresce o número de autores da atualidade que vão afirmar o caráter determinante das interações afetivas entre o bebê e seus cuidadores para o seu desenvolvimento cognitivo, simbólico, emocional e, em suma, de seu self. Podemos citar os trabalhos de Greenspan e Wieder (2000, 2006), de Hobson (1990, 1993a, 1993b, 1998, 2002, 2005a, 2005b, 2005c, 2007, 2009), e de Trevarthen (1977, 1980). Soma-se a eles os trabalhos de Stern (1985, 1995, 2004, 2010), que se tornaram uma referência para o tema do afeto no âmbito da Psicologia do Desenvolvimento. Sua teoria sobre a emergência de perspectivas para a organização da experiência subjetiva - senses of self (Stern, 1985, 1995, 2004), sensos de si (Brazão, 2008, 2012) - em estádios anteriores à atualização da competência linguística e à constituição da faculdade para a reflexão sobre si, sintetizada no eu, baseia-se na capacidade inata que o ser humano possui para estabelecer contato intersubjetivo afetivo com outros seres animados, evidenciando, naturalmente, os outros humanos como condição para sua humanização e socialização. Stern, de naturalidade suíça, desenvolve sua pesquisa tendo como principais pontos de apoio a Psicologia do Desenvolvimento e a Psicanálise, travando diálogo, principalmente, com autores como Trevarthen $(1977,1980)$ e Winnicott $(1945,1956,1958 a, 1958 b$, 1963, 1971).

\section{A teoria de Stern}

Dentre as teorias sobre o desenvolvimento humano da atualidade, a teoria de Stern insinua-se como particularmente interessante para os propósitos deste texto, pois, fora o fato dela possuir base afetiva, ela rompe com a tradição hegemônica moderna ao apresentar uma perspectiva de desenvolvimento não linear, não teleonômica, não subserviente ao vetor biológico, não centrada sobre o eu e essencialmente relacional (Brazão, 2008, 2012; Stern, 1985, 1995, 2004, 2010); além de introduzir e recorrer a conceitos amplamente utilizados por outros autores da Psicologia do Desenvolvimento. 
Na complexidade de sua tese, Stern vai diferir de teorias do desenvolvimento ortodoxas, como, por exemplo, a Epistemologia Genética desviando da orientação hierarquizante e da determinação biológica, fundamentos daquele sistema. Tampouco sua teoria é centrada num impulso, como a libido, nem tem como eixo vetorial o desenvolvimento do eu, mas gira em torno da emergência de perspectivas de organização da experiência subjetiva, caracterizadas como sensos de si (Brazão, 2008, 2012). Estas perspectivas são estabelecidas sobre capacidades inatas que o ser humano possui para estabelecer contato afetivo desde a mais tenra idade e encontram seu momento de organização em períodos de idade limites sem, contudo, se estruturarem em uma formação linear, estritamente hierárquica, na qual as últimas perspectivas englobariam as anteriores mantendo um ganho qualitativo sobre elas.

A hipótese fundamental da teoria de Stern (a emergência dos sensos de si) se apoia na capacidade que o ser humano possui para estabelecer interações afetivas com seu ambiente, em estádios muito precoces de sua vida (em torno de oito semanas de vida, o primeiro senso já está organizado), que proveriam o suporte para o subsequente desenvolvimento das capacidades cognitivas superiores, incluindo a linguagem, promovendo a socialização do indivíduo.

Stern propõe uma teoria para o desenvolvimento humano baseada na sequência cronológica da emergência dos sensos - por volta dos dois meses de idade, o senso de um si emergente se organiza; o senso de um si nuclear emerge entre dois e seis meses de vida; o senso de um si subjetivo entre sete e nove meses, e entre quinze e dezoito meses o senso de um eu verbal (Stern, 1985). No entanto, os sensos não formam uma composição hierarquizada. Não há diferenças qualitativas entre um e outro senso, num sentido evolucionista que possa lhes ser atribuído, que implique numa melhoria de estados sucessivos onde os estágios posteriores se definam por um progresso frente aos estados passados. Muito embora haja um ganho potencial na experiência global da criança, pois na organização de cada senso novas capacidades são conjugadas permitindo que uma experiência subjetiva mais rica seja atingida. A ideia de sequencialidade fica mantida sem que, contudo, nessa consecutividade os estados posteriores contenham em si qualquer ganho qualitativo sobre os estados anteriores (Stern, 1985, p. 11). Após a emergência dos quatro sensos (por volta dos 24 meses de idade), nenhum deles atrofia ou é absorvido pelos outros, mas há perspectivas simultâneas de experimentar a realidade que coexistem temporalmente sem haver privilégio ou hierarquia entre elas, produzindo uma experiência de integração de si permanentemente (Stern, 1985, p. 31).

O primeiro senso a se formar (por volta de oito semanas de vida) é o senso de um si emergente (Brazão, 2008, 2012) - sense of an emengent self (Stern, 1985, p. 37-68). Este primeiro senso é ainda uma forma muito incipiente de organização da experiência subjetiva. A ideia de processo em formação vem a ser utilizada e o autor sugere que a contínua formação e perenidade da experiência que se inicia nesse período perduram durante toda a vida. Este senso pode ser pensado como uma experiência de integração de estados afetivos e corporais, onde a consciência de si, como entidade autônoma, começa a ser ensaiada, sendo que é durante este momento que o bebê começa a estabelecer a conexão entre os seus atos e a experiência afetiva deles derivada.

Na hipótese de Stern haveria uma experiência de si, mesmo que elementar, constituindo-se como entidade autônoma desde as primeiras semanas de vida e, em nenhum momento, durante o desenvolvimento infantil, haveria uma experiência de indiferenciação absoluta (Stern, 1985, p. 10), aos moldes de estados fusionais, como pretendido pelas teorias hegemônicas em desenvolvimento humano da época (Piaget, 1964, 1970; Winnicott, 1945, 1956, 1958a, 1958b, 1963, 1971). A competência inata para a integração de estímulos sensoriais torna-se o fator chave para que a experiência de coesão se promova, tendo como referência o próprio corpo infantil, e para que a criança atribua a si a 
capacidade de ação sobre o ambiente (self agency), o que vem a ser a característica marcante deste senso.

Neste período (em torno de oito semanas) encontram-se amadurecidas capacidades fundamentais para que a relação entre a criança e o ambiente se estabeleça. Seriam elas: a percepção amodal, a percepção fisiognomônica e os afetos de vitalidade (Stern, 1985, p. 47-60), competências determinantes para o reconhecimento e expressão de traços afetivos que marcam as primeiras experiências intersubjetivas. Estas aptidões são meios pelos quais a criança percebe e organiza a realidade e, pela precocidade de sua emergência, estabelecem as condições para que as funções cognitivas superiores e a linguagem possam se desenvolver. Stern vai sinalizar que para a comunicação verbal se tornar um meio de trocas intersubjetivas é necessário que os interlocutores estejam engajados em uma relação e, para o autor, é o afeto que garante o estabelecimento desta relação prioritária, como se acompanha em:

A intersubjetividade é uma condição de humanidade. Sugiro que é também um sistema de motivação inato e primário, essencial para a sobrevivência da espécie e que goza de status comparável ao do sexo ou do apego. A própria linguagem não poderia emergir se não tivesse uma base intersubjetiva. Você só fala com alguém porque acredita que ele pode compartilhar sua paisagem mental e agir de acordo com ela (Stern, 2004, p. 119-125).

A percepção amodal é uma característica observada muito cedo em bebês. Fica sugerido que, desde as primeiras semanas de vida, os bebês apresentam a capacidade para desempenhar operação transmodal (cross modal - Stern, 1985, p. 51): transferência de informação entre modalidades sensoriais distintas que os permite reconhecer uma correspondência entre tato e visão, por exemplo. Isso significa receber uma informação via uma modalidade sensória e traduzi-la em outra modalidade. Presume-se que a informação é apreendida por suas propriedades integrais (as qualidades globais de qualquer experiência - compasso temporal, ritmo e duração
- conhecidas como atributos amodais) (Stern, 1985, p. 47) que não são visões, sons, toques ou objetos nomeáveis, mas contornos, intensidades e padrões temporais. Stern conduz um experimento em que, após vendar dois bebês de aproximadamente oito semanas de vida cada, oferece a um deles uma chupeta rugosa e ao outro uma chupeta lisa. Após a retirada das chupetas e das vendas, ele reapresenta as chupetas aos bebês e observa que cada um deles se orienta para a respectiva chupeta, insinuando haver, dessa maneira, a transferência de informação entre tato e visão (Stern, 1985, p. 47-51).

O bebê humano está capacitado a experimentar um mundo de unidade perceptual no qual ele pode perceber qualidades amodais através de qualquer via sensorial, conseguindo codificá-las em qualquer uma das modalidades sensoriais. Em se tratando de interações com outros humanos, a apreensão destas qualidades ocorre, principalmente, pela percepção das expressões faciais - percepção fisiognomônica (Stern, 1985) - onde traços faciais simples causariam impressões afetivas tais como a sensação de intensidade que é percebida como uma qualidade intrínseca da experiência. Um rosto humano é muito mais atraente para o bebê do que qualquer outra parte do corpo, mesmo as mãos. Esta atratividade é inata e se torna evidente por volta de oito semanas de vida acompanhada de outras mudanças no comportamento do bebê, como o sorriso responsivo e o acompanhamento visual, com o correspondente contato olho-a-olho. Estudos comportamentais apontaram a complexidade da micro-expressividade facial humana e do seu papel nas interações focais (Kendon, 1990). Sua variação chega a ser decisiva tanto em eventos simples, como a troca de um beijo entre namorados, quanto na realização de grandes negócios entre empresários, onde as relações entre o direcionamento do olhar, a posição das sobrancelhas e o movimento dos lábios (sem contar a fala e seu conteúdo) tornam-se meios, não conscientes, para se sintonizar com a afetividade dos envolvidos na interação e perceber suas intenções e emoções (Kendon, 1990). A complexa relação entre os componentes do rosto humano, intimamente ligados à expressão das emoções e da afetividade, 
capturam a atenção do bebê e servem de índice para a consequente apreensão das intenções e para o compartilhar de um foco de atenção comum.

Outra competência que surge nesta fase do desenvolvimento é o que Stern vai chamar de afetos de vitalidade (Stern, 1985, 1995, 2004, 2010). Os afetos de vitalidade são entendidos como formas particulares de afetos, com qualidades muito diferentes dos afetos categorizados (descritos por Darwin (1863) como medo, raiva, alegria, tristeza e seus derivados), sendo uma das vias mais efetivas pela qual o bebê distinguiria o que é animado do que é inanimado. Os afetos de vitalidade podem ocorrer vinculados aos afetos categorizados ou serem decorrentes de processos fisiológicos, próprios das vivências da criança. São experiências que podem ser mais bem compreendidas através de suas impressões dinâmicas, cinéticas, traduzidas como: crescendo, decrescendo, explodindo, enfraquecendo, falhando, surgindo etc., sempre conotando movimento. Um afeto de vitalidade do tipo "explodindo" pode ser experimentado como um aumento de intensidade afetiva até que se atinja um ponto culminante, como, por exemplo, do marejar dos olhos até o choro copioso, ou do leve sorriso até a gargalhada. Podendo estar vinculado a uma experiência de alegria, a um episódio de tristeza, a uma experiência que produza raiva ou medo, ou ainda, haver uma experiência de aumento progressivo de excitação interna (fisiológica). A modulação da intensidade afetiva, variando ao longo do tempo, pode ser sentida como um crescendo ou enfraquecendo, diminuindo ou aumentando. Em ambos os sentidos, essa variação produziria uma experiência dinâmica, sendo esse movimento a característica peculiar dos afetos de vitalidade. Em 2004, Stern usa a expressão contorno afetivo para caracterizar os afetos de vitalidade como impressões afetivas "de fundo", subjacentes a qualquer experiência, representando a variação em grau da intensidade afetiva ao longo de uma determinada duração de tempo (Stern, 2004, p. 84-92). Como exemplo, podemos pensar na experiência de se contemplar um pôr-do-sol, onde a gradação da intensidade do que se sente variará enquanto durar o pôr-do-sol.
Tanto os afetos de vitalidade, quanto a percepção amodal, são ferramentas que proporcionam a apreensão da experiência através de suas características mais globais. Remetem a um plano de experimentação pré-verbal, onde não haveria, ainda, a qualificação da experiência em categorias, como passa a ocorrer a partir da atualização da competência linguística. Os estímulos, pela percepção amodal, não são percebidos como oriundos deste ou daquele órgão sensorial especificamente, mas conjugam-se em uma representação supramodal, que remeteria a um plano de produção das formas e dos sentidos, primário a qualquer organização (Stern, 1985, p. 156).

Entre dois e seis meses de idade um novo senso se organiza e, com ele, novas aptidões entram em cena garantindo o enriquecimento da experiência subjetiva. O senso de um si nuclear (Brazão, 2008, 2012) - sense of a core self (Stern, 1985, p. 69-99) - emerge e com ele as experiências de autorregulação. Stern concebe a autorregulação como sendo a capacidade que o ser humano possui para regular os níveis de excitação corporal e os estados afetivos através da relação consigo mesmo ou com algum objeto externo, animado ou inanimado. Tais experiências sensoriais estão sempre associadas às experiências afetivas do bebê. Isso equivale a dizer que há uma relação direta entre a experiência sentida e o afeto ligado a essa experiência, que possibilita a criança vivenciar o modo como as expressões afetivas são sentidas através, por exemplo, de um toque sobre a sua pele ou pela tonalidade da fala de seus cuidadores (importância da linguagem tatibitati) (Greenspan \& Benderly, 1999). Haveria outras modulações possíveis da experiência de autorregulação, não se reduzindo estas a alterações puramente fisiológicas. De fato, a ênfase seria para as variações afetivas que são produzidas através dessa experiência. Para Stern, haveria uma "experiência concreta de estar com o outro (um outro autorregulador) tal que sentimentos de si seriam essencialmente alterados" (Stern, 1985 , p. 105). Sentimentos de segurança e de apego são desenvolvidos pelo contato e pela proximidade física, concorrendo para a produção de vínculo. A continuidade do contato corporal, principalmente com a 
mãe, é fundamental para que a intensidade de uma gama muito variada de afetos seja constantemente regulada, segundo Bowlby (1969). Porém, há uma diferença em relação a este aspecto em ambas as teorias, pois, ao contrário de Bowlby, Stern sugere que as trocas afetivas e o vínculo, propriamente dito, se desenvolvem com qualquer pessoa que mantiver um contato frequente com o bebê, sem haver o privilégio de que esta pessoa seja a mãe.

Quando o bebê está entre o sétimo e o nono mês de idade novas mudanças são percebidas em sua interatividade social e uma nova experiência subjetiva é atingida. O senso de um si subjetivo (Brazão, 2008, 2012) - sense of a subject self (Stern, 1985, p. 124-160) emerge conjuntamente com a experiência de compartilhar estados subjetivos. Nesse novo domínio de relações, "o foco muda de regular experiências para compartilhá-las" (Stern, 1985, p. 203), podendo agora ser atribuída à criança a capacidade para a intimidade psíquica e, com isso, as possibilidades intersubjetivas se expandem dramaticamente. Stern destaca a importância que essa experiência ocupa no desenvolvimento saudável do e de suas relações sociais apontando que a conectividade afetiva vem a ser a primeira forma de intersubjetividade que o ser humano experimenta, a qual define o desenvolvimento posterior das funções cognitivas superiores incluindo a linguagem. A interafetividade seria a primeira, a mais abrangente, e a mais imediata forma de compartilhar experiências subjetivas, segundo o autor.

Uma das primeiras experiências intersubjetivas que o bebê experimentaria seria a de "compartilhar intenções". Através da expressividade recíproca (troca de olhares entre bebê e o seu cuidador e pela percepção fisiognomônica) estabelece-se um contato dialógico através do qual seria possível a "compreensão da intenção do bebê" pelo seu cuidador e a intenção do cuidador pelo bebê (Stern, 1985, p. 204). Nesse sentido, a intersubjetividade possuiria dois níveis, por assim dizer. O primeiro nível, chamada de intersubjetividade primária (Trevarthen \& Aitkhen, 2001), é caracterizado pelas trocas interativas face-a-face, onde a responsividade do sorriso e do olhar entre o bebê e seus cuidadores vêm a ser os índices de que o desenvolvimento da criança encontra-se saudável. Por volta dos nove meses de idade, inicia-se a fase de intersubjetividade secundária e uma verdadeira "revolução" no desenvolvimento do bebê se inicia, pois é introduzido um objeto ou evento na relação entre ele e seus cuidadores. Este objeto, ou evento, passa a ser o foco do interesse de ambos, através da atenção compartilhada. O bebê desenvolve, então, novas habilidades, tais como: seguir o apontar do dedo, acompanhar o olhar da mãe/cuidador, apontar para algo, mostrar e dar para a mãe algum objeto, e a imitação (Carpenter, Nagell \& Tomasello, 1998).

Segundo Tomasello (2003), a atenção compartilhada é definida pelos comportamentos não verbais que o bebê utiliza para seguir, compartilhar ou direcionar a atenção do adulto para algum evento ou objeto do seu interesse. Compreende-se que seria a partir dos comportamentos de atenção compartilhada que as crianças demonstrariam intenções propriamente ditas, pois que, através da sua expressividade, olhar e gestos, elas procuram atingir determinado fim. Para Hobson (2005c), o exercício da atenção compartilhada só é possível quando o bebê está sintonizado afetivamente com a mãe/cuidador tornando-se, dessa forma, capaz de compartilhar estados afetivos. Stern cita, como exemplo, uma situação na qual a atenção compartilhada se torna decisiva para a ação do bebê. Diante de um objeto novo, que lhe cause afetos ambivalentes, que o atraiam e o assustem ao mesmo tempo, o bebê, ao engatinhar na direção do objeto, busca na expressão do seu cuidador indícios sobre a sua ação. Nesse momento, a troca de olhares entre ambos, com a correspondente expressão afetiva facial, dará a medida para a ação, revelando a concordância ou discordância do cuidador em relação à aproximação ou distanciamento do bebê frente ao objeto. Para o autor, esse é um tipo de evento no qual o compartilhar de intenções e de afetos se torna evidente como experiência intersubjetiva, tendo como foco um objeto comum a ambos (Stern, 1985, p. 132). Seria ainda pelo desenvolvimento da 
atenção compartilhada que o bebê ingressaria no mundo de significados, propriamente falando, pois é a partir desta competência que estados mentais tornam-se experiências intersubjetivas e que a criança desenvolve a chamada teoria da mente (Hobson, 2002), sendo capaz de inferir que o outro humano atribui significados diversos a eventos e objetos dentro de seu contexto social.

Com a emergência do senso de um si subjetivo, surge um fenômeno que aparentemente seria uma simples imitação, uma "responsividade empática" (Stern, 1985, p. 141). No entanto, este fenômeno envolve processos mais complexos do que a simples imitação de gestos corporais e incluiriam estados subjetivos compartilhados. É desta forma que Stern apresenta a sintonia afetiva (Brazão, 2008, 2012) - affect attunement (Stern, 1985 p. 140). Enquanto a imitação diria respeito à forma do comportamento, contendo a ideia de alguma expressão mais objetiva, a sintonia afetiva diria respeito ao sentimento de fundo, ao estado subjetivo compreendido na experiência, incluindo a performance, intensidades afetivas, níveis de excitação diversos, expressividade facial e exteriorização emotiva (Stern, 1985). A sintonia afetiva opera através da capacidade transmodal, ou seja, os canais sensoriais para a recepção e expressão do estado afetivo seriam diferentes nas duas pessoas envolvidas na experiência, não havendo, com isso, o necessário pareamento gestual. O que estaria sendo equiparado, não seria um comportamento em si, mas "algum aspecto do comportamento que reflete o estado afetivo pessoal" (Stern, 1985, p. 142).

As características da sintonia afetiva contribuem para formar a dimensão múltipla das experiências subjetivas presentes em estádios do desenvolvimento infantil pré-verbais, tornando-se os precursores do desenvolvimento das funções cognitivas e demais habilidades de interação social (Stern, 1985, p. 146). Seria através da capacidade que o ser humano possui para identificar equivalências amodais (percepção amodal e transmodal) que, além de produzir o sentimento de uma experiência unificada - a realidade sendo apreendida em seu aspecto global -, permitiria o "engajamento em sintonia afetiva para alcançar intersubjetividade afetiva" (Stern, 1985, p. 156). Nesse sentido, as vias afetivas tornam-se os meios privilegiados para que a sintonia afetiva produza seus efeitos. Não somente os afetos discretos categorizados (alegria, tristeza, medo etc.), mas, principalmente, os afetos de vitalidade serviriam como instrumentos pelos quais a sintonia viria a ser operada, pois "manifestam-se em todo comportamento" (Stern, 1985, p. 157). A sintonia afetiva se configura como um dos dispositivos mais eficientes para que o ser humano dimensione seu universo existencial, já que estados subjetivos que não são compartilhados com frequência geram afetos de solidão, desertificação e isolamento afetivo e social.

É claro que a comunhão interpessoal, como criada pela sintonia, desempenhará um papel importante no porvir da criança em reconhecer que estados sentimentais internos são formas da experiência humana que são compartiIhados com outros humanos. O reverso é também verdadeiro: estados sentimentais que nunca são sintonizados serão experimentados somente sozinhos, isolados do contexto interpessoal da experiência compartilhável. O que estaria destacado aqui seria nada menos que a forma e a extensão do universo interno compartilhável (Stern, 1985, p. 152).

Em torno do décimo oitavo mês de vida da criança, a linguagem emerge, produzindo uma expansão fantástica nas suas interações sociais, e com ela o senso de um eu verbal se constitui (Brazão, 2008, 2012) - sense of a verbal self (Stern, 1985, p. 162). A partir desse momento, os conteúdos mentais e afetivos, além de já serem compartilhados intersubjetivamente, tornam-se possíveis de serem expressos verbalmente, permitindo duas pessoas criarem experiências mútuas de significados (Stern, 1985, p. 182). Com a linguagem presente, a relação intersubjetiva ganha novas dimensões. Contudo, Stern salienta os impasses que se apresentam com a emergência da linguagem. Pelo privilégio que a fala ocupa nas relações interpessoais, em nossa sociedade, as vias afetivas são rapidamente deslocadas para uma posição secundária, 
entre os meios de comunicação intersubjetiva. Esse deslocamento, ao longo do tempo, gera consequências, sendo a mais imediata delas a oclusão da percepção de estados afetivos pessoais e intersubjetivos, pois a linguagem, ilusoriamente, conseguiria explicitar com maior precisão certos conteúdos que eram compartilhados pelas vias comunicativas que a precediam. A ilusão se dá na suposição de que a linguagem conseguiria expressar integralmente tais conteúdos. O autor adverte que determinadas nuanças da experiência subjetiva não podem ser fraturadas a fim de serem traduzidas pela linguagem, já que sua organização ocorre nos domínios de relação constituídos pelos sensos pré-verbais. Além disso, as propriedades amodais da experiência não podem ser fragmentadas a fim de serem traduzidas, pois sua apreensão só pode ser alcançada globalmente. Com isso, ao se tentar traduzir determinadas experiências através da linguagem, incorre-se no risco de empalidecê-las, extraindo delas aspectos imprescindíveis da sua organização (Stern, 1985, p. 174-177). Como expressar pela fala o sentimento causado pela contemplação de uma obra de arte, ou pela queima de fogos de fim de ano? Como relatar fielmente o que se experimenta no contato do corpo com a água do mar, por exemplo? Essas e outras experiências afetivas não são passíveis de serem traduzidas integralmente pela linguagem, quando muito se consegue uma descrição detalhada do evento, ficando o sentimento elidido no relato.

\section{Interatividade afetiva no desenvolvimento humano}

A teoria de Stern aponta a precocidade e a necessidade que a experiência afetiva ocupa no desenvolvimento típico. Capacidades como a percepção amodal, a percepção fisiognomônica e a sintonia afetiva, baseada nos afetos de vitalidade, formam a base para que funções como a linguagem e o desenvolvimento do self se realizem. De fato, devido ao caráter essencialmente relacional de sua teoria, Stern vai afirmar que toda a socialização e desenvolvimento humano só se tornam possíveis pela interatividade afetiva (Stern, 1985, 1995, 2004).
Em trabalhos atuais na Psicologia do Desenvolvimento, o afeto vem ganhando destaque. Artigas-Pallares e Paula (2012), Diniz e Koller (2010), Fiore-Correia e Lampreia (2012), Garcia e Lampreia (2011), Lampreia (2007) e Oliveira (2009) apontam o papel que a conexão afetiva, definida por Hobson (2002) como a capacidade inata de expressividade, responsividade e sensibilidade do recém-nascido ao afeto do outro, ocupa como índice do desenvolvimento saudável infantil e como instrumento de intervenção clínica em síndromes como o autismo. $\mathrm{O}$ autismo, como concebido por Kanner (1943), seria um distúrbio do contato afetivo, com comprometimento das interações sociais, da comunicação e marcado pela presença de comportamentos repetitivos e estereotipados. A identificação da síndrome tem sido feita, fundamentalmente, baseada nas dificuldades para a orientação para estímulos sociais, para o contato face-a-face com acompanhamento do olhar, para a atenção compartilhada, para a imitação motora e para o jogo simbólico (Baron-Cohen, Allen \& Gillberg, 1992).

O distúrbio da atenção compartilhada tem sido considerado um dos indicadores mais eficientes do autismo. De acordo com Tomasello (1995) e Tomasello e Farrar (1986), a partir do desenvolvimento da atenção compartilhada, é possível se predizer o desenvolvimento da linguagem. A perspectiva desenvolvimentista tem como direção procurar compreender as peculiaridades e desvios do desenvolvimento da criança com transtorno do espectro do autismo (TEA), ou com risco de autismo, tendo como referência os padrões do desenvolvimento típico. As peculiaridades do autismo envolvem uma falha no desenvolvimento dos precursores da linguagem, isto é, da comunicação não verbal. De acordo com Hobson (2002) faltaria ao bebê que irá desenvolver um quadro autista a responsividade afetiva, a qual seria a responsável pelo engajamento pessoa a pessoa, para o desenvolvimento das habilidades para a conexão emocional e para a comunicação não verbal, características de socialização que encontram seu suporte nas capacidades de percepção amodal, percepção fisiognomônica e de sintonia afetiva, como descritas por Stern (1985). 
Conforme o DSM 5 (American Psychiatric Association, 2014) o transtorno do espectro autista é caracterizado por um déficit persistente na comunicação social e na interação em distintos contextos. Dentro deste critério se incluem problemas na reciprocidade social e emocional, déficit nas condutas comunicativas verbais e não verbais e dificuldades para desenvolver e manter relações apropriadas com outros humanos de seu ambiente. $\mathrm{Na}$ atividade motora a criança portadora deTEA manifestaria padrões de conduta, interesse ou atividade restritos, repetidos e estereotipados, a hipo ou a hiper reatividade a estímulos sensoriais ou o interesse não usual nos aspectos sensoriais de seu entorno. Segundo Hobson, Chidambi, Lee, \& Meyer (2006), seria pela falha na capacidade de estabelecer conexão afetiva que as crianças com TEA teriam o desenvolvimento das funções cognitivas e de interação social comprometidas, sofrendo um desvio comparado ao desenvolvimento de crianças típicas.

Tendo como referência a teoria de Stern, indivíduos com transtorno do espectro do autismo (TEA) não desenvolveriam adequadamente os sensos mais básicos - senso de um si emergente e senso de um si nuclear (Brazão, 2008, 2012) -, responsáveis pelas experiências de autocoerência (capacidade inata de integrar estados afetivos às suas ações) e de autoagência (capacidade de atribuir a si um comportamento ou uma ação sobre um objeto externo), dentre outras habilidades específicas coemergentes com estes sensos, expressas através, por exemplo, da capacidade que a criança apresenta de manter contato ocular nas interações face-a-face com seus cuidadores. Em consequência, a experiência de integração sensório-afetiva, necessária para a criança se constituir, falha, comprometendo o desenvolvimento dos sensos posteriores (senso de um si subjetivo e senso de um eu verbal), onde a intersubjetividade alcançaria seus níveis mais complexos. Nesse processo alterado, o senso de um si subjetivo (Brazão, 2008, 2012) não se constitui e as experiências por ele mediadas, tais como a sintonia afetiva, o compartilhar de estados afetivos, de intenções, do foco de atenção, da orientação comum para um objeto ou evento (intersubjetividade secundária) (Trevarthen \&
Aitken, 2001), não se realizam adequadamente, comprometendo o desenvolvimento da competência linguística que se concluiria com a emergência do senso de um eu verbal, por volta de dezoito meses de idade, conforme sugere o autor em: "Supõe-se ser esta uma das razões pelas quais crianças autistas têm tanta dificuldade com a aquisição da linguagem" (Stern, 2004, p. 125).

Entretanto, a despeito da suspeita de que as crianças com risco de autismo, e mesmo aquelas já diagnosticadas com a síndrome, apresentariam uma deficiência em sua capacidade inata para a conexão afetiva, pesquisas recentes com enfoque desenvolvimentista têm sugerido que um dos caminhos mais efetivos de trabalho com estas crianças seria através da intervenção precoce, antes mesmo dos doze meses de idade (Fiore-Correia, 2010; Garcia \& Lampreia, 2011; Lampreia, 2007; Oliveira, 2009), com estímulo de suas habilidades potenciais para a interafetividade e para a comunicação verbal e não verbal (Fiore-Correia, 2010; Lampreia, 2007). Os programas para o tratamento do autismo baseados em uma abordagem desenvolvimentista, SCERTS (Social Comunication, Emotional Regulation \& Transactional Support) e DIR (Developmental, Individual-Difference, Relationship-Based), afirmam a importância que o desenvolvimento dos recursos comunicativos e das habilidades que capacitam a criança a interagir em seu ambiente social, possuem para amenizar os sintomas da síndrome. $\mathrm{O}$ objetivo seria o de desenvolver, de acordo com as capacidades individuais, comportamentos próprios do desenvolvimento infantil típico, possibilitando, dessa forma, uma maior integração social dos portadores da síndrome (Greenspan \& Wieder, 2006; Klinger \& Dawson, 1992; Prizant, Wetherby, Rubin, \& Laurent, 2003).

\section{Considerações finais}

Embora não haja unanimidade entre as teorias em Psicologia no que tange à relevância que o afeto ocupa no desenvolvimento humano, em geral há concordância sobre a influência que ele exerce na socialização do indivíduo, mesmo em teorias de base genética. Todavia, 
de acordo com a abordagem desenvolvimentista, a influência do afeto não se circunscreve à socialização individual apenas, mas encontra-se presente tanto na constituição do individuo, ou seja, o afeto seria um fator intrínseco ao processo de desenvolvimento, quanto na sua integração à sociedade. De fato, de acordo com este ponto de vista, compreende-se que homem e sociedade estão amalgamados em um mesmo bloco indissociável, não sendo possível distinguir quem produz o quê, pois produto, produtor e processo, se encontram consolidados em um mesmo ato. Com isso, mais e mais o afeto eleva-se em grau de importância para a compreensão das produções humanas e para o desenvolvimento do próprio homem.

Foi delineada sinteticamente, no presente texto, a trajetória do afeto no âmbito da Psicologia do Desenvolvimento, tomando como ponto de referência os trabalhos de Henri Wallon e as contribuições da corrente sócio-histórica russa que, em muito, enriqueceram a perspectiva desenvolvimentista, oferecendo uma alternativa teórica frente ao determinismo genético. Um dos objetivos do texto foi o de apontar o crescente reconhecimento do afeto como agente mediador nas relações intersubjetivas e de seu caráter imprescindível no desenvolvimento das funções cognitivas superiores, incluindo a linguagem.

Tomamos por bem apresentar a teoria contemporânea de Daniel N. Stern, da emergência dos sensos de si, pela sua clareza na definição de conceitos comumente usados por autores de tradição desenvolvimentista, bem como da ênfase que ele aplica às habilidades humanas para estabelecer relações afetivas desde períodos muito precoces de vida, realçando a necessidade da conexão afetiva para a interatividade da criança com o seu ambiente e para a sua socialização. Ficou sugerido que falhas na capacidade inata para a conexão afetiva comprometeriam o desenvolvimento adequado dos sensos primários, ocasionando prejuízos severos na interatividade social e no subsequente desenvolvimento dos sensos seguintes, inibindo a emergência de competências que permitem experiências tais como a de compartilhar estados subjetivos, afetivos e mentais mais complexos.

Salientamos, também, a atenção que tem sido dada à interatividade afetiva no tratamento de crianças com TEA, ou com risco de desenvolverem o transtorno. Na atualidade, são relevantes os trabalhos que atestam a importância que a conexão afetiva deve ocupar em programas de intervenção precoce de base desenvolvimentista e, embora os avanços que se tem conseguido na redução das dificuldades causadas pelo transtorno ainda sejam discretos, fica sugerido que o futuro desenvolvimento de programas e de metodologias mais elaboradas, que incluam a interatividade afetiva em seus conteúdos de trabalho, possam contribuir com maior eficácia para a redução dos déficits do autismo. 


\section{José Carlos Chaves Brazão}

Doutor em Psicologia pela Universidade Federal Fluminense - RJ. Brasil.

E-mail: zebraza@grupochi.com.br/ josecbrazao@gmail.com

\section{Endereço para envio de correspondência:}

Rua Noronha Torrezão, 407/1002 BL - XII. CEP: 24240-185. Niterói - RJ. Brasil.

Recebido: 12/03/2014 1ª Reformulação: 14/03/2014 Aprovado: 05/12/2014 


\section{Referências}

American Psychiatric Association (2014). Manual diagnóstico e estatístico de transtornos mentais. DSM-5. Porto Alegre, RS: Artmed.

Artigas-Pallares, J., \& Paula, I. (2012). El autismo 70 años después de Leo Kanner y Hans Asperger. Revista de la Asociación Espanola de Neuropsiquiatría, 32(115), 567-587.

Baron-Cohen, S., Allen, J., \& Gillberg, C. (1992). Can autism be detected at 18 months? The needle, the haystack, and the CHAT. British Journal of Psychiatry, 161, 839-843.

Bowlby, J. (1969). Apego. São Paulo, SP: Martins Fontes.

Brazão, J.C. (2008). Entre mim e ti conosco o que há? A relação clínica uma experiência limiar. Dissertação de Mestrado, Departamento de Pós-Graduação de Psicologia, Universidade Federal Fluminense, RJ.

Brazão, J.C. (2012). O vínculo como uma experiência afetiva, pelo primado da relação: Uma perspectiva transdisciplinar. Tese de Doutorado, Departamento de PósGraduação de Psicologia, Universidade Federal Fluminense, RJ.

Carpenter, M., Nagell, K., \& Tomasello, M. (1998). Social cognition, joint attention, and communicative competence from 9 to 15 months of age. Monographs of the Society for Research in Child Development, 63(4), 1-143.

Darwin, C. (1863). A expressão das emoções no homem e nos animais. São Paulo, SP: Cia das Letras.

Descartes, R. (1999). Meditações. In Os Pensadores. São Paulo, SP: Nova Cultural. (Trabalho original publicado em 1641).

Diniz, E., \& Koller, S. H. (2010). O afeto como um processo de desenvolvimento ecológico. Educar em Revista, (36), 65-76.

Fiore-Correia, O. B. (2010). O papel da conexão afetiva na construção de um programa de intervenção precoce para crianças recémdiagnosticadas autistas ou com risco autístico. Tese de doutorado, Departamento de Psicologia, Pontifícia Universidade Católica do Rio de Janeiro, Rio de Janeiro.
Fiore-Correia, O., \& Lampreia, C. (2012). A conexão afetiva nas intervenções desenvolvimentistas para crianças autistas. Psicologia: Ciência e Profissão, 32(4), 926-941.

Garcia, M. L., \& Lampreia, C. (2011). Limites e possibilidades da identificação de risco de autismo no primeiro ano de vida. Psicologia: Reflexão e Crítica, 24(2), 300-308.

Greenspan, S., \& Benderley, B. (1999). A evolução da mente: As origens da inteligência e as novas ameaças a seu desenvolvimento (M. Monte, trad.). Rio de Janeiro, RJ: Record.

Greenspan, S., \& Wieder, S. (2000). A developmental approach to difficulties in relating and communicating in autism spectrum disorders and related syndromes. In A. Wetherby, \& B. Prizant (Orgs.). Autism spectrum disorders. A transactional developmental perspective (pp. 279-231). Baltimore: Paul H. Brookes.

Greenspan, S., \& Wieder, S. (2006). Engaging autism: Using the floortime approach to help children relate, communicate and think. Cambridge: Da Capo Lifelong.

Hobson, P. (1990). On acquiring knowledge about people and the capacity to pretend: Response to Leslie (1987). Psychological Review, 97(1), 114-121.

Hobson, P. (1993a). Autism and development of mind. Hove, Sussex: Erlbaum.

Hobson, P. (1993b). The emotional origins of social understanding. Philosophical Psychology, 6(3), 1-27.

Hobson, P. (1998). The intersubjective foundations of thought. In S. Bråten (Ed.), Intersubjective communication and emotion in early ontogeny (pp. 283-296). Cambridge, III: Cambridge University Press.

Hobson, P. (2005a). Autism and emotion. In F. R. Volkmar, R. Paul, A. Klin, \& D. Cohen (Eds.). Handbook of autism and pervarsive developmental disorders (Vol 1, 3rd. ed., pp. 406-422). New York: Wiley.

Hobson, P. (2007). Communicative depth: Soundings from developmental psychopathology. Infant Behavior \& Development, 30, 267-277. 
Hobson, P. (2005b). Social engagement and understanding in chimpanzees and humans. Monographs of the Society for Research in Child Development, 70(1), 133-152.

Hobson, P. (2002). The cradle of thought. London: Macmillan.

Hobson, P. (2005c). What puts the jointness into joint attention? In N. Eilan, C. Hoerl, T. McComarck, \& J. Roessler (Eds.), Joint attention: Communication and other minds (pp. 185-204). Oxford: Wiley.

Hobson, P. (2009). Wittgenstein and the developmental psychopathology of autism. In New Ideas in Psychology, 27, 243-257.

Hobson, P., Chidambi, G., Lee, A., \& Meyer, J. (2006). Foundations for self-awareness: An exploration through autism. Monographs of the Society for Research in Child Development, 71(2), 1-188.

Kanner, L. (1943). Autistic disturbances of affective contact. Nervous Child, 2, 217-250.

Kendon, A. (1990) Conducting interaction: Patterns of behavior in focused encounters. Cambridge, III: Cambridge University Press.

Klinger, L., \& Dawson, G. (1992). Faciliting early social and communicative developmental in children with autism. In S. Warren, \& J. Reichle (Eds.). Causes and effects in communication and language intervention (pp. 157-186). Baltimore: Paul H. Brookes.

Koyré, A. (1963). Considerações sobre Descartes (2a ed.). Lisboa: Presença.

Lampreia, C. (2007). A perspectiva desenvolvimentista para a intervenção precoce no autismo. Estudos de Psicologia, 24(1): 105-114.

Maturana, H. (2001). Cognição, ciência e vida cotidiana. Belo Horizonte, MG: Editora UFMG.

Maturana, H. (1998). Emoções e linguagem na educação e na política (J. F. C. Fortes, trad.). Belo Horizonte, MG: UFMG.

Maturana, H., \& Varela, F. (1984). A árvore do conhecimento. São Paulo, SP: Palas Athena.

Maturana, H., \& Verden-Zöller, G. (1993). Amar e brincar: Fundamentos esquecidos do humano. São Paulo, SP: Palas Athena.
Oliveira, S. M. (2009). A clínica do autismo sob uma perspectiva desenvolvimentista: O papel do engajamento afetivo no desenvolvimento da comunicação e da linguagem. Dissertação de Mestrado, Departamento de Psicologia da PUC-Rio, Rio de Janeiro.

Passos, E. (1992). O sujeito cognoscente entre o tempo e o espaço. Tese de doutorado, Departamento de Psicologia, Universidade Federal do Rio de Janeiro, Rio de Janeiro.

Piaget, J. (1964). A formação do símbolo da criança: Imitação,jogo e sonho imagem e representação. Neuchâtel: Delachaux et Niestlé.

Piaget, J. (1967). Seis estudos de psicologia. Rio de Janeiro: Forense-Universitária.

Piaget, J. (1970). A epistemologia genética. In Os Pensadores. São Paulo: Abril Cultural.

Prizant, B., Wetherby, A., Rubin, E., \& Laurent, A. (2003). The SCERTS model: A transactional, family-centered approach to enhancing communication and socioemotional abilities of children with autism spectrum disorder. Infants and Young Children, 16(4), 296-316.

Spinoza, B. (2007). Ética (2a ed., T. Tadeu, trad.). São Paulo, SP: Autêntica.

Stern, D. (2010). Forms of vitality: Exploring dynamic experience in psychology, the arts, psychoteraphy, and development. Oxford: Oxford University Press.

Stern, D. (2004). O momento presente na psicoterapia e na vida cotidiana. Rio de Janeiro, RJ: Record.

Stern, D. (1985). The interpersonal world of the infant: A view from psychoanalysis and developmental psychology. New York, NY: Basic Books.

Stern, D. (1995). The motherhood constellation: A unified view of parent-infant psychoterapy. New York, NY: Basic.

Tomasello, M. (1995). Joint attention as social cognition. In C. Moore, \& P. J. Dunham (Orgs.). Joint attention: Its origins and role in development (pp.103-130). Hillsdale, NJ: Lawrence Erlbaum.

Tomasello, M. (2003). Origens culturais da aquisição do conhecimento humano (C. Berliner, trad.). São Paulo, SP: Martins Fontes. 
Tomasello, M., \& Farrar, M. J. (1986). Joint attention and early language. Child Development, 57(6), 1454-1463.

Trevarthen, C. (1977). Descriptive analyses of infant communicative behavior. In $\mathrm{H}$. R. Schaffer (Ed.), Studies in mother-infant interaction. New York, NY: Academic Press.

Trevarthen, C. (1980). The foundations of intersubjectivity: Development of interpersonal and cooperative understanding in infants. In D. R. Olson (Ed.)., The social foundation of language and thought: Essays in honor of Jerome Bruner. New York, NY: Norton.

Trevarthen, C., \& Aitken, K. (2001). Infant intersubjectivity: Research, theory and clinical applications. Journal of Child Psychology and Psychiatric, 42(1), 3-48.

Valsiner, J. (1988). Ontogeny of co-construction of culture within socially organized environment settings. In J. Valsiner (Org.), Childdevelopmentwithinculturallystructured environments: social co-construction and environmental guidance in development (pp. 283-297). Norwood, NJ: Ablex.

Vasconcellos, V., \& Valsiner, J. (1995). Perspectiva co-construtivista na psicologia e na educação. Porto Alegre, RS: Artes Médicas.

Wallon, H. (1971). As origens do caráter na criança: Os prelúdios do sentimento de personalidade. São Paulo, SP: Difusão Européia do Livro.
Wallon, H. (1942). De l'acte à la pensée. Paris: Armand Colin.

Wallon, H. (1968). La evolución psicológica del nino. Barcelona: Crítica.

Wallon, H. (1986). O papel do outro na consciência do eu. In Werebe, M. J., NadelBrufert, J. Henri Wallon. São Paulo, SP: Ática.

Winnicott, D. W. (1945) Primitive emotional development. In New York, NY: Basic., (Collected Papers Through Paediatrics to Psycho-analysis).

Winnicott, D. W. (1956) Primary maternal preoccupation. In Winnicott, D. W. Collected papers through pediatrics to pscychoanalysis (pp. 300-305). New York, NY: Basic.

Winnicott, D. W. (1958a) The first year of life: Modern views on the emotional development. In Winnicott, D. W. The family and the individual development. London: Tavistock.

Winnicott, D. W. (1958b) The capacity to be alone. In Winnicott, D. W. The maturational processes and the facilitating environment: Studies in the theory of emotional development (pp .29-36). New York, NY: International Universities Press.

Winnicott, D. W. (1963) From dependence towards independence in the development of the individual. In Winnicott, D. W. The maturational processes and the facilitating environment. studies in the theory of emotional development (pp. 83-92). New York, NY: International Universities Press.

Winnicott, D. W. (1971) Play and reality. Gretna: Pelican. 